\title{
Climate Change and the Olivine Concept
}

\section{Schuiling RD*}

Department of Geosciences, Universiteit Utrecht, Netherlands

*Corresponding author: Schuiling RD, Department of Geosciences, Universiteit Utrecht, Netherlands, Tel: +31 302535006 ; E-mail: R.D.Schuiling@uu.nl

Received date: Mar 16, 2017; Accepted date: Mar 18, 2017; Published date: Mar 21, 2017

Copyright: (c) 2017 Schuiling RD. This is an open-access article distributed under the terms of the Creative Commons Attribution License, which permits unrestricted use, distribution, and reproduction in any medium, provided the original author and source are credited.

\section{Short Communication}

Life on Earth (including yours!) exists thanks to the weathering of rocks. That process has captured the $\mathrm{CO}_{2}$ that is emitted by volcanoes and stored it as carbonate rocks. It works as follows. Minerals like olivine, the most common mineral on Earth, react with $\mathrm{CO}_{2}$ and water, resulting in magnesium bicarbonate solutions. These are carried by rivers to the sea, where organisms turn it into carbonate rocks, the sustainable stores for $\mathrm{CO}_{2}$.

Humankind is now causing a spike in $\mathrm{CO}_{2}$ emissions because we burn in a few hundred years the fossil fuels that have taken hundreds of millions of years to form. Weathering cannot cope with this fiftyfold increase in emission, so the $\mathrm{CO}_{2}$ concentrations of the atmosphere rise, leading to climate change and ocean acidification.

A logical answer would be to increase the rate of weathering as well to reach a new balance. Mine olivine rocks, mill them and spread the grains over fields and beaches. Small field tests in the Netherlands have shown that this works. Wastes of similar crushed rocks or even construction wastes also show very high rates of weathering.

Many people prefer complicated technologies to fight climate change, and raise several objections to this simple olivine concept. Allegedly it would be dangerous because olivine rocks contain asbestos (a misleading statement, there are some olivine rocks that carry asbestos, but these should be left untouched).

It would contain high levels of nickel: True, but that doesn't make them dangerous. There are hundreds of millions of people living on such rocks, grow their crops on them, graze their animals and drink the water without ANY negative consequences.

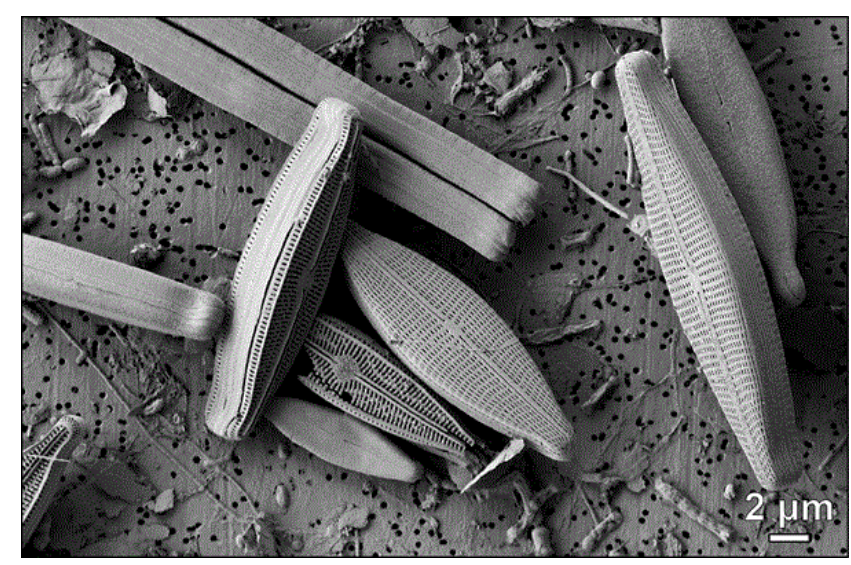

Figure 1: Diatoms from the mine pit lake of former asbestos mine.
An often heard objection is that the process would be too slow. It is a slow process, but it doesn't matter that it takes a few years before the olivine grains are completely weathered. For the climate that is good enough, and quite a bit quicker and more effective than all those big international climate meetings together.

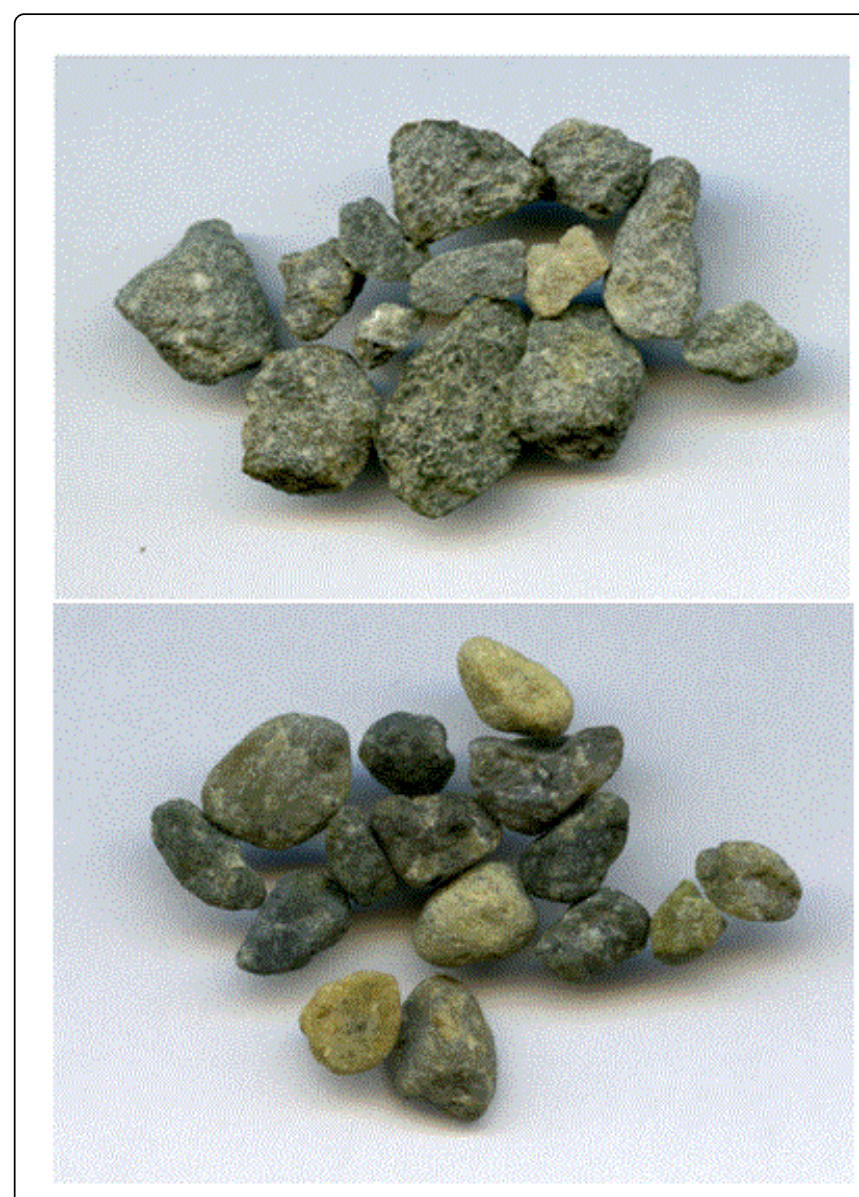

Figure 2: Before the experiment, the olivine grit is angular and rough (top), after a few days of quiet rotation the grains are rounded and polished (bottom).

Then the more serious objections. Olivine is a silicate, so it releases silica. It was stated that the process will stop itself when the solubility of quartz $\left(\mathrm{SiO}_{2}\right)$ is reached. Fortunately, this idea is not valid, because there are many organisms like rice. Sugar cane, bamboo and reed that need silica, and so does a very large group of plankton, the so-called diatoms (siliceous algae (Figure 1)). The dissolved silica is gobbled up by them, so in the real world the solubility of quartz is never reached by olivine weathering. 
Page 2 of 2

In another widely cited paper it was claimed that olivine sand on beaches would take 700-2100 years to weather, unless it would be ground at high cost to micron-sized slivers. The authors apparently live in a world where water is immobile, and mineral grains on the beach don't move for many centuries, despite tides, surf, currents or storms.

Experiments have shown that grains on the beach collide, abrade each other and are quickly losing micron-sized slivers that weather in a few days instead of 2100 years (Figure 2). Our answer, therefore, would be that the surf is the largest ball-mill on Earth, and is free of charge. Another objection in that paper was that the olivine grains would form a passivating reaction layer on their surface, which would stop the reaction. This objection is negated by the next wave, which removes such layers.

It seems that people prefer to raise nonsense objections, instead of embracing the best natural and cheap solution for our big problems, Olaf Schuiling. 